\title{
Magnetic Properties of $\mathrm{Li}_{3} \mathrm{~V}_{2}\left(\mathrm{PO}_{4}\right)_{3} / \mathrm{Li}_{3} \mathrm{PO}_{4}$ Composite
}

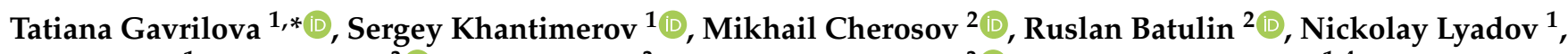 \\ Ivan Yatsyk ${ }^{1}$, Yulia Deeva ${ }^{3}{ }^{\mathbb{D}}$, Denis Turkin ${ }^{3}$, Tatiana Chupakhina ${ }^{3}{ }^{-1}$ and Nail Suleimanov ${ }^{1,4}$ \\ 1 FRC Kazan Scientific Center of RAS, Zavoisky Physical-Technical Institute, Sibirsky Tract, 10/7, \\ 420029 Kazan, Russia; khantim@mail.ru (S.K.); nik061287@mail.ru (N.L.); i.yatzyk@gmail.com (I.Y.); \\ nail.suleimanov@mail.ru (N.S.) \\ 2 Institute of Physics, Kazan Federal University, Kremlyovskaya Str., 18, 420008 Kazan, Russia; \\ mcherosov@gmail.com (M.C.); tokamak@yandex.ru (R.B.) \\ 3 Institute of Solid State Chemistry UB RAS, Pervomaiskaya Str., 91, 620990 Ekaterinburg, Russia; \\ juliahik@mail.ru (Y.D.); den-turkin@yandex.ru (D.T.); chupakhina@yandex.ru (T.C.) \\ 4 Institute of Electric Power Engineering and Electronics, Kazan State Power Engineering University, \\ Krasnoselskaya Str., 51, 420066 Kazan, Russia \\ * Correspondence: tatyana.gavrilova@gmail.com
}

\section{check for} updates

Citation: Gavrilova, T.; Khantimerov, S.; Cherosov, M.; Batulin, R.; Lyadov, N.; Yatsyk, I.; Deeva, Y.; Turkin, D.; Chupakhina, T.; Suleimanov, N. Magnetic Properties of

$\mathrm{Li}_{3} \mathrm{~V}_{2}\left(\mathrm{PO}_{4}\right)_{3} / \mathrm{Li}_{3} \mathrm{PO}_{4}$ Composite. Magnetochemistry 2021, 7, 64. https:// doi.org/10.3390/magnetochemistry 7050064

Academic Editor:

Krzysztof Chwastek

Received: 10 April 2021

Accepted: 9 May 2021

Published: 12 May 2021

Publisher's Note: MDPI stays neutral with regard to jurisdictional claims in published maps and institutional affiliations.

Copyright: (c) 2021 by the authors. Licensee MDPI, Basel, Switzerland. This article is an open access article distributed under the terms and conditions of the Creative Commons Attribution (CC BY) license (https:/ / creativecommons.org/licenses/by/ $4.0 /)$.

\begin{abstract}
Here, we present the investigation of the magnetic properties of $\mathrm{Li}_{3} \mathrm{~V}_{2}\left(\mathrm{PO}_{4}\right)_{3} / \mathrm{Li}_{3} \mathrm{PO}_{4}$ composites, which can be potentially used as a cathode material in lithium-ion batteries. $\mathrm{Li}_{3} \mathrm{~V}_{2}\left(\mathrm{PO}_{4}\right)_{3} / \mathrm{Li}_{3} \mathrm{PO}_{4}$ was synthesized by the thermal hydrolysis method and has a granular mesoporous structure. Magnetic properties of the composite were investigated using magnetometry and electron spin resonance methods. Based on magnetization measurements, the simultaneous existence of the paramagnetic phase with antiferromagnetic interactions between spins of $\mathrm{V}^{3+}$ ions and magnetically correlated regions was suggested. Most probably, magnetically correlated regions were formed due to antisite defects and the presence of $\mathrm{V}^{4+}$ ions that was directly confirmed by electron spin resonance measurements.
\end{abstract}

Keywords: $\mathrm{Li}_{3} \mathrm{~V}_{2}\left(\mathrm{PO}_{4}\right)_{3}$; composite; cathode material; magnetization; electron spin resonance

\section{Introduction}

The interest in alternative energy sources has been increasing every year over the past two decades. Among the different energy alternatives, the conversion into chemical energy is the most convenient, and rechargeable batteries are the most popular energy storage devices. Currently, one can see the exciting developments in new positive electrode (cathode) materials for these batteries including nickel-rich layered oxides, lithium-rich layered oxides, high-voltage spinel oxides, and high voltage polyanionic compounds [1,2]. Among them, the monoclinic $\mathrm{Li}_{3} \mathrm{~V}_{2}\left(\mathrm{PO}_{4}\right)_{3}$ with promising electrochemical properties including excellent cycling stability, high theoretical capacity, low synthetic cost, improved safety characteristic, and low environmental impact has emerged as a highly suitable candidate for use in lithium-ion batteries (LIB) [3,4]. Recently, significant achievements in electrochemical performance in $\mathrm{Li}_{3} \mathrm{~V}_{2}\left(\mathrm{PO}_{4}\right)_{3}$ have been achieved by utilizing advanced nanotechnologies, for example, nanostructured $\mathrm{Li}_{3} \mathrm{~V}_{2}\left(\mathrm{PO}_{4}\right)_{3}$ hybrid cathodes such as nanoparticles, nanowires, nanoplates, nanospheres, and others [5], and on the other hand, by introducing conductive carbon additives (carbon coated particles) [6-9] or some oxides such as $\mathrm{SiO}_{2}, \mathrm{ZrO}_{2}$, and others [3,10-13]. Another way to improve the charge transfer in the $\mathrm{Li}_{3} \mathrm{~V}_{2}\left(\mathrm{PO}_{4}\right)_{3}$ system is the substitution of both the transition element and its ligands $[3,7,13,14]$.

Generally, it is known that the transition element in $\mathrm{Li}_{3} \mathrm{~V}_{2}\left(\mathrm{PO}_{4}\right)_{3}$ changes its valence state in the lithium intercalation/deintercalation process $[15,16]$, indicating that the movement of lithium ions and the transfer of electrons can take place simultaneously. This mechanism can be realized in the case of the localized electron model. Moreover, the preference of the localized electrons model is proven by the fact that many cathode materials 
are poor conductors [17] and their conductivity is most likely caused by the excited carriers than the band conduction electrons [18]. In this model, the charge transfer is possible between transition ions of different valences directly or more often indirectly through the nearest ligand environment. The stable pathway of the electron transfer is realized due to the hybridization of $\mathrm{d}$ - and p-electronic orbitals of the transition elements and ligand surrounding them, respectively. At the same time, this hybridization can lead to the presence of the magnetic interaction between ions of transition elements and the appearance of different types of magnetic ordering. Any fluctuations, the crystal structure deformation due to the doping process, fluctuations of the chemical composition in composites and others, can lead to a change in the degree of orbital overlap and as a result, to simultaneously change the electron mobility and magnetic properties. Moreover, the fluctuation of the chemical composition can lead to enhanced ion mobility [19].

Therefore, the study of the local fluctuations in chemical composition and their effect on magnetic properties becomes important in connection with the experimentally observed relationships between electrical and magnetic properties. The investigation of the influence of the localized electron spin direction and the magnetic structure on the electron transfer between ions of different valences is of particular interest. In this regard, experiments on the study of the magnetic properties of cathode materials using highly sensitive local methods such as magnetometry and electron spin resonance are of great importance. Here, we present the magnetic properties study of the $\mathrm{Li}_{3} \mathrm{~V}_{2}\left(\mathrm{PO}_{4}\right)_{3} / \mathrm{Li}_{3} \mathrm{PO}_{4}$ system using the magnetometry and electron spin resonance methods. The investigated $\mathrm{Li}_{3} \mathrm{~V}_{2}\left(\mathrm{PO}_{4}\right)_{3} / \mathrm{Li}_{3} \mathrm{PO}_{4}$ composite system was obtained by the thermal hydrolysis method and, among others, this system is promising in terms of improving the electrochemical properties of cathode materials using $\mathrm{Li}_{3} \mathrm{PO}_{4}$ as an additional phase [20,21].

\section{Experimental}

\subsection{Sample Synthesis and Characterization}

In this paper, the investigated $\mathrm{Li}_{3} \mathrm{~V}_{2}\left(\mathrm{PO}_{4}\right)_{3} / \mathrm{Li}_{3} \mathrm{PO}_{4}(\mathrm{LVPO} / \mathrm{LPO})$ solid solution was obtained by the thermal hydrolysis method with subsequent annealing in an Ar atmosphere. The synthesis was carried out according to the following scheme:

(i) Chemically pure lithium carbonate $\mathrm{Li}_{2} \mathrm{CO}_{3}$, phosphoric acid $\mathrm{H}_{3} \mathrm{PO}_{4}$, vanadium (IV) oxide $\mathrm{V}_{2} \mathrm{O}_{5}$, and oxalic acid $\mathrm{C}_{2} \mathrm{H}_{2} \mathrm{O}_{4}$ were used in stoichiometric molar ratios as starting materials. An excess amount of lithium carbonate $\mathrm{Li}_{2} \mathrm{CO}_{3}$ and phosphoric acid $\mathrm{H}_{3} \mathrm{PO}_{4}$ was used to obtain the second phase $\left(\mathrm{Li}_{3} \mathrm{PO}_{4}\right)$ in the amount of $7.5 \mathrm{~mol}$. \%. The reagents, in stoichiometric molar ratio, were mixed in a Teflon beaker for thermal hydrolysis using 20 $\mathrm{mL}$ of distilled water for the homogenization of the reaction mixture.

(ii) The annealing was carried out at $180^{\circ} \mathrm{C}$ for $36 \mathrm{~h}$. The cooling was carried out at room temperature without air access.

(iii) The resulting green-gray precursor was dried at $350{ }^{\circ} \mathrm{C}$ in an argon flow to remove moisture.

(iv) The dried precursor was calcined in two steps at 850 and $875^{\circ} \mathrm{C}$ in the presence of carbon (5 mas. \%) in an argon flow during $5 \mathrm{~h}$. During the synthesis, the carbon reduced vanadium ions accompanied by the formation of gaseous carbon monoxide and carbon dioxide, which were removed from the reaction zone with an argon flow. Carbothermal reduction, as a rule, is realized at temperatures above $800^{\circ} \mathrm{C}$, while the temperatures of the phase formation of $\mathrm{Li}_{3} \mathrm{~V}_{2}\left(\mathrm{PO}_{4}\right)_{3}$, depending on the synthesis method, can vary over a wide range-from 700 to $1200{ }^{\circ} \mathrm{C}$ [22]. The final removal of carbon from the reaction mixture was confirmed by the complete dissolution of the synthesis product in nitric acid.

The composition of the obtained sample was controlled using a Shimadzu XRD-7000 S automatic diffractometer with of $0.03^{\circ}$ step in the $10^{\circ}-70^{\circ}$ range with an exposure of $2 \mathrm{~s}$ at a point. The phase analysis of the reaction products was performed using the crystallographic database "Database of Powder Standard-PDF2" (ICDD, Newtown Square, PA, USA, Release 2009). X-ray pattern processing was performed according to the Rietveld method using the FULLPROF-2018 software. According to the x-ray diffraction data (Figure 1), the 
resulting product was a $\mathrm{Li}_{3} \mathrm{~V}_{2}\left(\mathrm{PO}_{4}\right)_{3}(92.5 \mathrm{~mol}$ \% $) / \mathrm{Li}_{3} \mathrm{PO}_{4}(7.5 \mathrm{~mol}$. \%) composite. The crystal structure of the $\mathrm{Li}_{3} \mathrm{~V}_{2}\left(\mathrm{PO}_{4}\right)_{3}$ phase belongs to the monoclinic space group $P 2_{1} / n$ (\#14) with unit cell parameters $a=8.606(1) \AA, b=8.587(4) \AA, c=12.032(1) \AA, \alpha=\gamma=90^{\circ}, \beta$ $=90.554^{\circ}(1)$, and $\mathrm{V}=889.1(2) \AA^{3}$. The crystal structure of the $\mathrm{Li}_{3} \mathrm{PO}_{4}$ phase belongs to the orthorhombic space group Pnma (\#62), $a=6.146 \AA, b=10.453 \AA, c=4.913 \AA, \alpha=\beta=\gamma 90^{\circ}$, and $\mathrm{V}=315.64 \AA^{3}$. In comparison, the mesoporous sample of $\mathrm{Li}_{3} \mathrm{~V}_{2}\left(\mathrm{PO}_{4}\right)_{3} / \mathrm{C}(\mathrm{LVPO} / \mathrm{C})$ was synthesized by the soft-template method [16,23], similarly to $\mathrm{Na}_{3} \mathrm{~V}_{2}\left(\mathrm{PO}_{4}\right)_{3}[24-26]$. The unit cell parameters for the $\mathrm{Li}_{3} \mathrm{~V}_{2}\left(\mathrm{PO}_{4}\right)_{3} / \mathrm{C}$ material were $a=8.6095 \AA, b=8.6041$ $\AA, c=12.0560 \AA$, and $\beta=90.490^{\circ}$ and its cell volume was estimated to be $893.044 \AA^{3}$ (space group $\mathrm{P} 21 / n$ ) [23]. The observed here difference between the crystal structure parameters for the two samples is quite common in the literature, so one can see that the lattice parameters can slightly differ depending on the synthesis process and monoclinic axis selection [27-32].

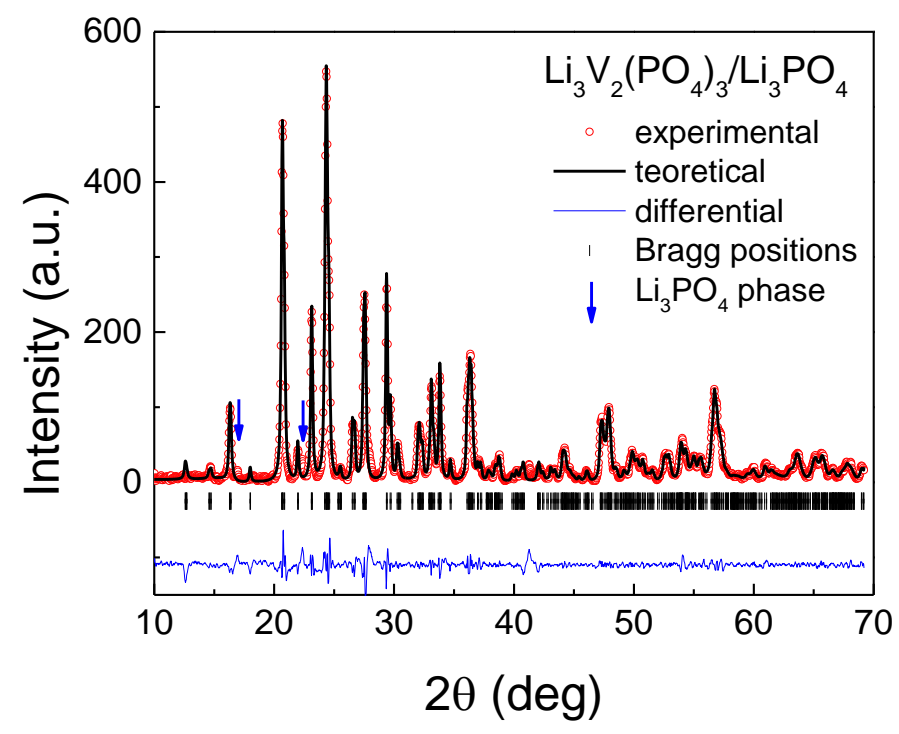

Figure 1. Experimental, theoretical, and differential diffraction patterns of the $\mathrm{Li}_{3} \mathrm{~V}_{2}\left(\mathrm{PO}_{4}\right)_{3} / \mathrm{Li}_{3} \mathrm{PO}_{4}$ composite.

The morphology of $\mathrm{Li}_{3} \mathrm{~V}_{2}\left(\mathrm{PO}_{4}\right)_{3} / \mathrm{Li}_{3} \mathrm{PO}_{4}$ solid solution was investigated using scanning electron microscopy (SEM) via an EVO 50 XVP scanning electron microscope. SEM images of the $\mathrm{Li}_{3} \mathrm{~V}_{2}\left(\mathrm{PO}_{4}\right)_{3} / \mathrm{Li}_{3} \mathrm{PO}_{4}$ surface are shown in Figure 2 . It was interesting to compare the results of the electron microscopy measurements of our samples and samples with carbon additives (LVPO/LPO (Figure 2) and LVPO/C composites (see Figure 2 in [23]), respectively). From the SEM images, one can see that composites had a granular structure with closed values of the average grain sizes.

\subsection{Experimental Details}

The magnetization was measured using a commercial PPMS-9 platform (Quantum Design, USA) in the temperature range from 5 to $305 \mathrm{~K}$ in field-cooled (FC) and zero field-cooled (ZFC) regimes. The magnetic hysteresis loops were measured in the magnetic field range of $1 \mathrm{~T}$.

Electron spin resonance (ESR) spectrum of the $\mathrm{Li}_{3} \mathrm{~V}_{2}\left(\mathrm{PO}_{4}\right)_{3} / \mathrm{Li}_{3} \mathrm{PO}_{4}$ composite was measured on an ER 200 SRC (EMX/plus) spectrometer (Bruker, Germany) at the frequency of $9.4 \mathrm{GHz}$ at room temperature using a double rectangular $\mathrm{x}$-band resonator ER 4105DR. This equipment allows for the simultaneous detection of the electron spin resonance spectrum of the investigated sample and benchmark spectrum. The measured spectra were approximated using an open-source MATLAB toolbox for simulating and fitting a wide range of electron paramagnetic resonance spectra-EasySpin software package [33]. 


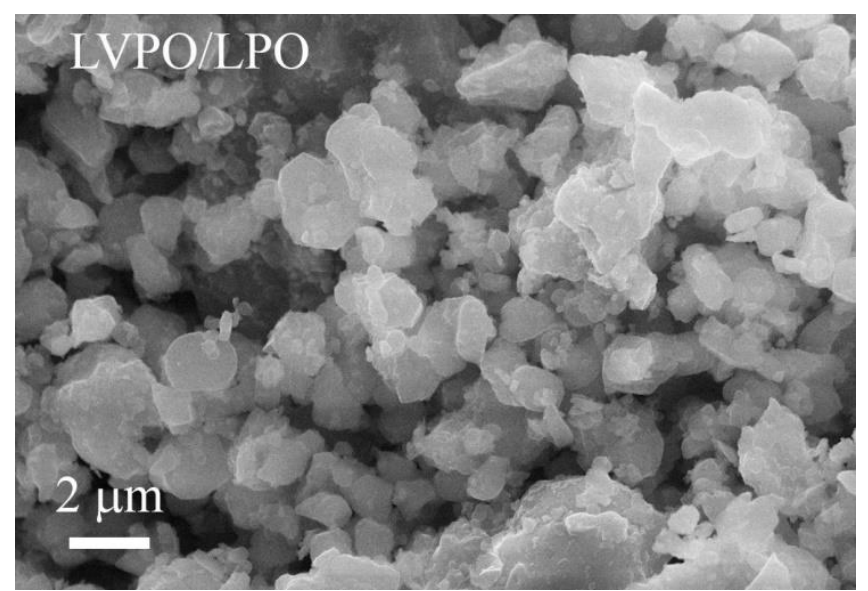

(a)

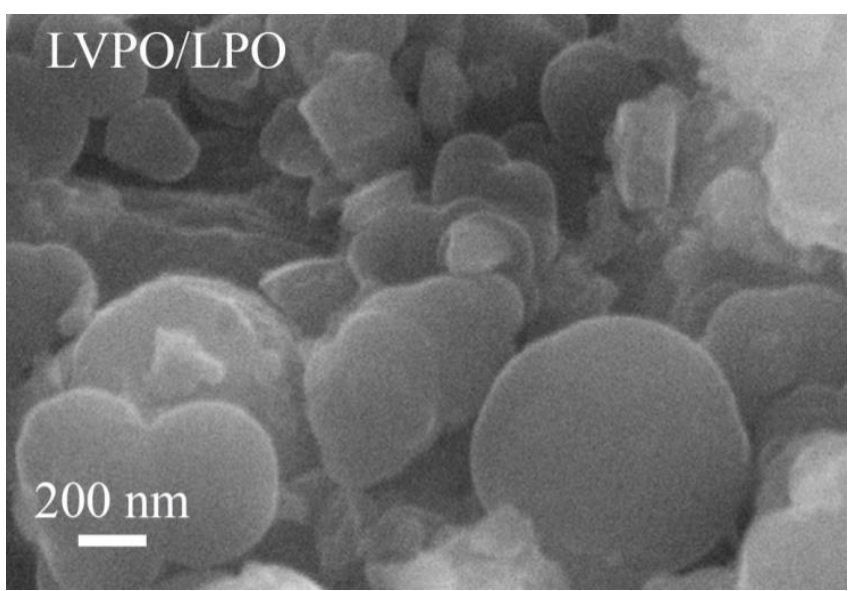

(b)

Figure 2. SEM images of the $\mathrm{Li}_{3} \mathrm{~V}_{2}\left(\mathrm{PO}_{4}\right)_{3} / \mathrm{Li}_{3} \mathrm{PO}_{4}$ composite at different magnification.

\section{Results and Discussion}

\subsection{Magnetization}

The magnetization of the $\mathrm{Li}_{3} \mathrm{~V}_{2}\left(\mathrm{PO}_{4}\right)_{3} / \mathrm{Li}_{3} \mathrm{PO}_{4}(\mathrm{LVPO} / \mathrm{LPO})$ sample as a function of temperature ( $\mathrm{M}-\mathrm{T}$ curve) was measured in magnetic field $\mathrm{H}=0.1 \mathrm{~T}$ in the $\mathrm{FC}$ regime (Figure 3). In all investigated temperature ranges, the magnetization of $\mathrm{Li}_{3} \mathrm{~V}_{2}\left(\mathrm{PO}_{4}\right)_{3} / \mathrm{Li}_{3} \mathrm{PO}_{4}$ decreased with an increase in temperature. At temperatures above $\mathrm{T}>120 \mathrm{~K}$, the inverse magnetic susceptibility is linear and can be well fitted by the Curie-Weiss law $\chi=C /$ (T$\theta_{\mathrm{CW}}$ ), where $C$ is the Curie constant and $\theta_{\mathrm{CW}}$ is the Curie-Weiss temperature (inset in Figure 3). The high temperature approximation of the experimental data by the Curie-Weiss law gives the negative values of the Curie-Weiss temperature $\theta_{C W}=-68 \mathrm{~K}$, which suggests the antiferromagnetic nature of the exchange interactions between spins in the investigated sample. Higher absolute value of the Curie-Weiss temperature in LVPO/LPO indicates stronger magnetic interactions in this sample compared to others. The known from the literature value of the Curie-Weiss temperature $\theta_{\mathrm{CW}}=-37 \mathrm{Kwas}$ obtained by Cahill et al. [34], proving the antiferromagnetic nature of exchange interactions in $\mathrm{Li}_{3} \mathrm{~V}_{2}\left(\mathrm{PO}_{4}\right)_{3}$ regardless of the synthesis method. The inset in Figure 3 shows inverse dependences of molar susceptibility, calculated taking into account the compositions of the composites $(7.5 \mathrm{~mol}$. $\%$ of $\mathrm{Li}_{3} \mathrm{PO}_{4}$ or $8 \%$ of carbon [23]). The approximation of inverse dependences of molar susceptibility gives the value of Curie constants $C=1.9 \mathrm{emu} \cdot \mathrm{mol}^{-1} \mathrm{Oe}^{-1}$ for $\mathrm{LVPO} / \mathrm{LPO}$ and $C=0.84 \mathrm{emu} \cdot \mathrm{mol}^{-1} \mathrm{Oe}^{-1}$ for $\mathrm{LVPO} / \mathrm{C}$, respectively. The effective magnetic moment can be obtained from the Curie constants as:

$$
\mu_{e f f}=\sqrt{3 k_{B} C / N_{A}}
$$

where $k_{B}$ is the Boltzmann constant; $C$ is the Curie constant; and $N_{A}$ is the Avogadro constant. The obtained $\mu_{\text {eff }}$ was equal to $3.9 \mu_{\mathrm{B}}$ for LVPO/LPO and $2.59 \mu_{\mathrm{B}}$ for LVPO/C, respectively. Taking into account that the magnetic ion $\mathrm{V}^{3+}$ has a $3 \mathrm{~d}^{2}$ electronic configuration and ground state ${ }^{3} \mathrm{~F}$ with spin $S=1$, let us estimate the effective magnetic moment $\mu_{\text {eff }}$ as:

$$
\mu_{\text {theor }}=g \cdot \sqrt{Z \cdot S \cdot(S+1)} \cdot \mu_{B}
$$

where $\mu_{B}$ is the Bohr magneton; $g$ is the Lande $g$-factor; $Z$ is the number of magnetic ions in a unit cell; and $S$ is the spin. Taking into account that $g=1.95$ [16] for vanadium ions, one obtains the effective magnetic moment per mole of $\mu_{\text {theor }}=3.9 \mu_{\mathrm{B}}$. Theoretical and experimental values of the effective magnetic moment for the LVPO/LPO composite coincided very well, which confirms the valence state of the vanadium ions as $\mathrm{V}^{3+}$. The difference between the theoretical and experimental values of the effective magnetic moment for the 
LVPO/C composite is most likely associated with the higher carbon content in the sample compared to the data from [23]. In this case, the composite had a lower molar mass, which was used in calculating the data in the inset of Figure 3 and, therefore, the Curie constant and effective magnetic moment.

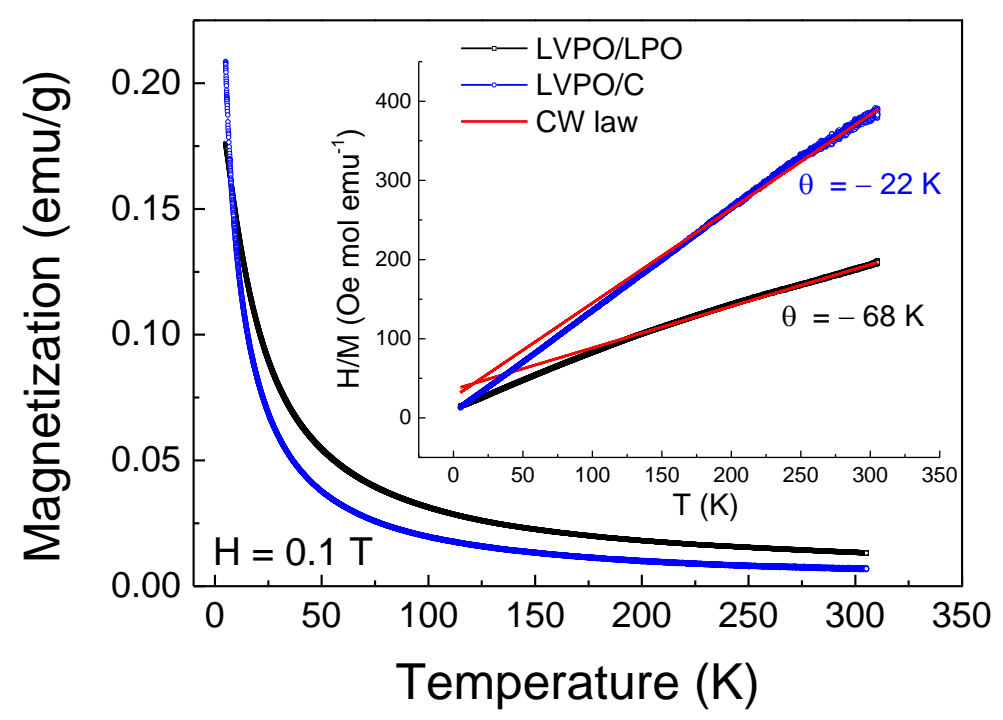

Figure 3. Temperature dependencies of magnetization $\mathrm{M} / \mathrm{H}$ of the $\mathrm{Li}_{3} \mathrm{~V}_{2}\left(\mathrm{PO}_{4}\right)_{3} / \mathrm{Li}_{3} \mathrm{PO}_{4}$ sample in comparison with the $\mathrm{Li}_{3} \mathrm{~V}_{2}\left(\mathrm{PO}_{4}\right)_{3} / \mathrm{C}$ powder sample measured in the $\mathrm{FC}$ regime in the external magnetic field $\mathrm{H}=0.1 \mathrm{~T}$. Inset shows the temperature dependence of the inverse magnetic susceptibility $\mathrm{H} / \mathrm{M}$; solid line corresponds to the Curie-Weiss law (see details in the text).

In addition to the above-mentioned experiments, the magnetization measurements in the ZFC-FC regimes in low magnetic field $\mathrm{H}=5 \mathrm{mT}$ (Figure 4) were performed to determine the temperature below which magnetic correlations become dominant over thermal fluctuations. The ZFC-FC splitting was observed in LVPO/LPO below $\mathrm{T}_{\text {split }}$ $=120 \mathrm{~K}$, while in LVPO/C, this splitting was not observed. This splitting proves the above-mentioned suggestion of the presence of more significant short-range magnetic correlations in LVPO/LPO compared to LVPO/C. Isothermal magnetization measurements as a function of the external magnetic field below $120 \mathrm{~K}$ in LVPO/LPO (Figure 5) showed that in the investigated field range up to $\mathrm{H}=1 \mathrm{~T}$, the $\mathrm{M}-\mathrm{H}$ curves were linear without any tendency to saturation. Most probably, the magnetic ordering was realized below $\mathrm{T}=5 \mathrm{~K}$.

Obviously, magnetic correlations in the LVPO/LPO sample can lead to the existence of ferromagnetically ordered regions. The appearance of these regions can be explained by the anti-site cation exchange, namely the occupation of transition metal sites by Li and vice versa, which is the typical point defects in crystal lattices and the topic of extraordinary research interest in solid state physics and chemistry. In the case of $\mathrm{Li}_{3} \mathrm{~V}_{2}\left(\mathrm{PO}_{4}\right)_{3}$, the occupation of the $\mathrm{V}$ site by the Li ion changes the charge allocation in the vicinity of this anti-site defect and freed electrons redistribute between neighboring ions of vanadium. De Gennes et al. [35] showed that in such a localized state, the small ferromagnetic cluster of the nearest neighboring vanadium ions can be formed due to the indirect exchange interaction between them, which was proven experimentally for the $\mathrm{Li}_{\mathrm{x}} \mathrm{Mn}_{1-\mathrm{x}}$ Se system $[36,37]$. The simultaneous existence of the paramagnetic phase with antiferromagnetic correlations and magnetically correlated regions, which form due to structural defects and the presence of the mixed-valence magnetic ions, was also previously observed in ytterbium manganites [38,39] and $\mathrm{La}_{\mathrm{x}} \mathrm{Sr}_{2-\mathrm{x}} \mathrm{Fe}_{\mathrm{x}} \mathrm{Ti}_{1-\mathrm{x}} \mathrm{O}_{4}$ compounds [40]. 


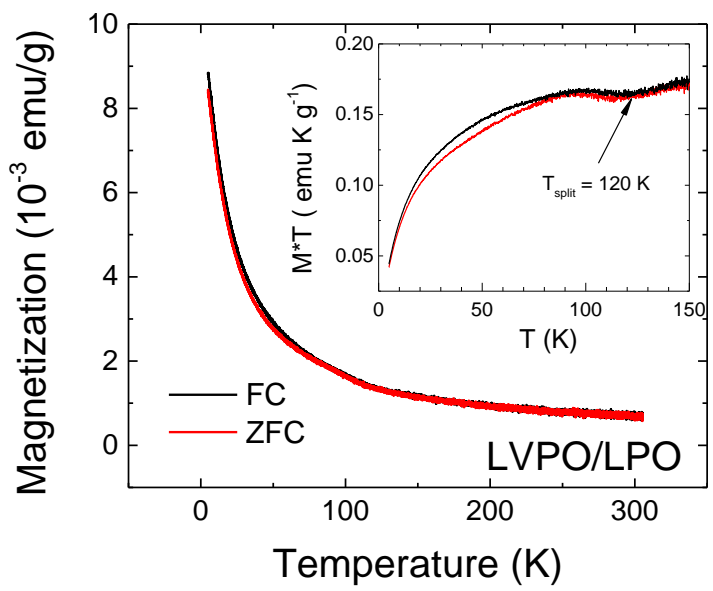

(a)

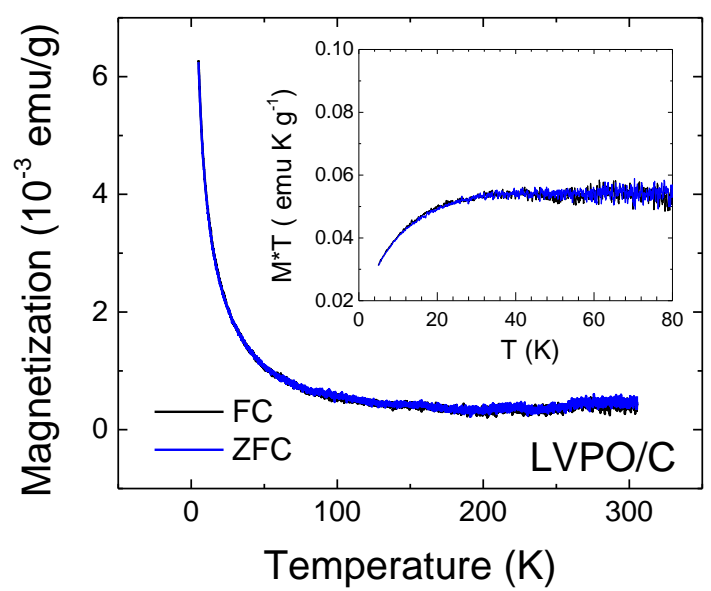

(b)

Figure 4. Temperature dependence of magnetization in (a) $\mathrm{Li}_{3} \mathrm{~V}_{2}\left(\mathrm{PO}_{4}\right)_{3} / \mathrm{Li}_{3} \mathrm{PO}_{4}$ and $(\mathbf{b}) \mathrm{Li}_{3} \mathrm{~V}_{2}\left(\mathrm{PO}_{4}\right)_{3} / \mathrm{C}$ measured in $\mathrm{FC}$, $\mathrm{ZFC}$ regimes in the external magnetic field of $\mathrm{H}=5 \mathrm{mT}$. Insets show the low temperature data in representation $\mathrm{M} \cdot \mathrm{T}$ vs. $\mathrm{T}$ in more detail.

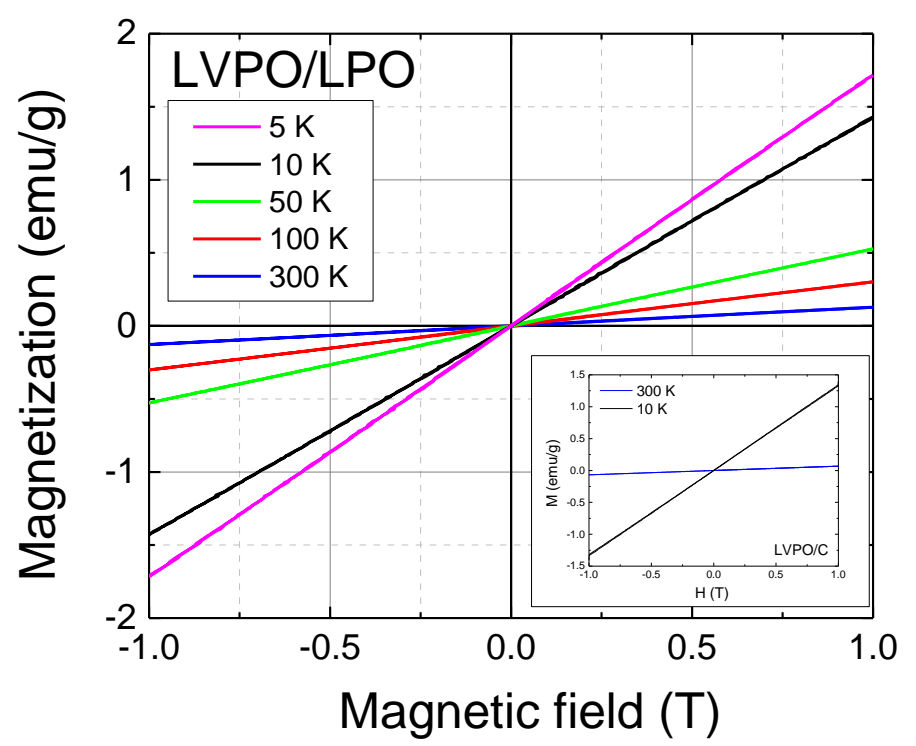

Figure 5. Magnetization as a function of the external magnetic field in the $\mathrm{Li}_{3} \mathrm{~V}_{2}\left(\mathrm{PO}_{4}\right)_{3} / \mathrm{Li}_{3} \mathrm{PO}_{4}$ composite at different temperatures. Inset shows data for $\mathrm{Li}_{3} \mathrm{~V}_{2}\left(\mathrm{PO}_{4}\right)_{3} / \mathrm{C}$.

\subsection{Electron Spin Resonance}

As was above-mentioned, $\mathrm{V}^{3+}$ in an even number of electrons in the respective electronic shells and singlet ground-state levels may result so that no ESR is observable. At the same time, we were able to resolve two resonance signals in the ESR spectra of the $\mathrm{Li}_{3} \mathrm{~V}_{2}\left(\mathrm{PO}_{4}\right)_{3} / \mathrm{Li}_{3} \mathrm{PO}_{4}$ composite at room temperature (Figure 6). The first signal was observed in high magnetic fields. Approximation of this signal yielded the best fit of the experimental data for the powder spectrum, corresponding to the paramagnetic centers with effective spin $S=1 / 2$ and anisotropic g-factor $g_{\perp}=1.963, g_{||}=1.934$ and the value of the linewidth $\Delta \mathrm{H}=1.64 \mathrm{mT}$. The observed anisotropic g-factor is the characteristic feature of most polyanionic cathode compounds where the transition element is localized in the tetragonally distorted octahedral crystal field. This was also the case for the $\mathrm{Li}_{3} \mathrm{~V}_{2}\left(\mathrm{PO}_{4}\right)_{3}$ [16]. Thus, the observed ESR spectra is most probably due to a small amount of $\mathrm{V}^{4+}$ ions $\left(3 \mathrm{~d}^{1}, \mathrm{~S}=1 / 2\right)$. The second signal with $\mathrm{g}=2$ most likely represents a signal from dangling bonds or radicals and no particular interest. To estimate the number of $\mathrm{V}^{4+}$ 
ions, the integral intensity of the $\mathrm{Li}_{3} \mathrm{~V}_{2}\left(\mathrm{PO}_{4}\right)_{3} / \mathrm{Li}_{3} \mathrm{PO}_{4}$ spectrum was compared with the same parameters for the benchmark (inset in Figure 6). The integral intensities ratio of the sample $\left(\mathrm{N}_{\mathrm{LVPO} / \mathrm{LPO})}\right.$ and the reference $\left(\mathrm{N}_{0}\right)$ was equal to $\mathrm{N}_{\mathrm{LVPO} / \mathrm{LPO}} / \mathrm{N}_{0}=4.81$, which corresponds to the number of magnetic centers $\mathrm{N}_{\mathrm{LVPO} / \mathrm{LPO}}=7.7 \cdot \times 10^{17}$ (about 10 percent of total vanadium ions). The change in the valence state of vanadium ions and the presence of $\mathrm{V}^{4+}$ can be associated with insignificant lithium non-stoichiometry or anti-site defects (the occupation of $\mathrm{V}$ sites by $\mathrm{Li}$ and vice versa) in the investigated compound. The presence of anti-site defects can lead to the formation of ferromagnetically correlated clusters, which is confirmed by the above measurements of magnetization.

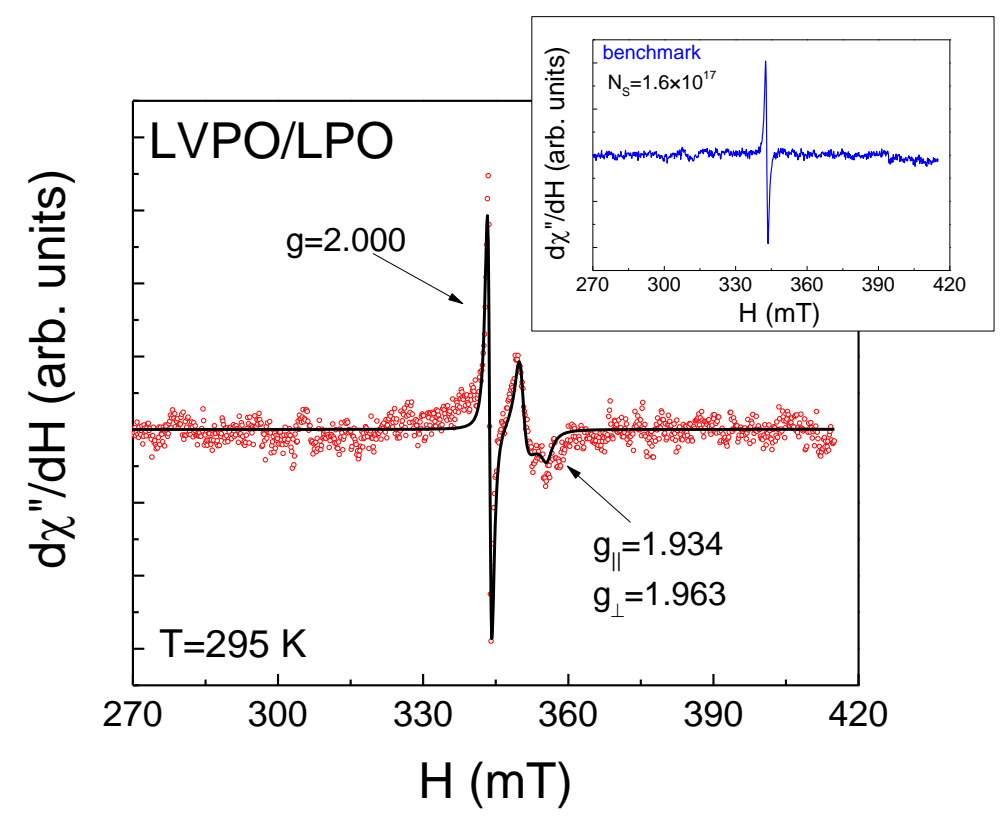

Figure 6. Electron resonance spectrum of the $\mathrm{Li}_{3} \mathrm{~V}_{2}\left(\mathrm{PO}_{4}\right)_{3} / \mathrm{Li}_{3} \mathrm{PO}_{4}$ composite at room temperature at the $\mathrm{X}$-band frequency. Symbols correspond to the experimental data, solid lines indicate fits by the powder sample spectra using the EasySpin software package. Inset shows the electron spin resonance spectrum of the benchmark containing $N=1.6 \times 10^{17}$ magnetic spins.

\section{Conclusions}

Here, we present the synthesis details and magnetic properties investigations of the $\mathrm{Li}_{3} \mathrm{~V}_{2}\left(\mathrm{PO}_{4}\right)_{3} / \mathrm{Li}_{3} \mathrm{PO}_{4}$ composite, which can be potentially used as a cathode material in a lithium-ion battery. The $\mathrm{Li}_{3} \mathrm{~V}_{2}\left(\mathrm{PO}_{4}\right)_{3} / \mathrm{Li}_{3} \mathrm{PO}_{4}$ composite was synthesized by the thermal hydrolysis method and contained $7.5 \mathrm{~mol} . \%$ of $\mathrm{Li}_{3} \mathrm{PO}_{4}$ phase. It had a granular structure and consisted of nanoscale particles with a monolithic structure. Magnetization measurements of $\mathrm{Li}_{3} \mathrm{~V}_{2}\left(\mathrm{PO}_{4}\right)_{3} / \mathrm{Li}_{3} \mathrm{PO}_{4}$ indicate that above $\mathrm{T}>120 \mathrm{~K}$, the investigated sample was in the paramagnetic state and exhibited Curie-Weiss like behavior. The negative value of the Curie-Weiss temperature $\theta=-68 \mathrm{~K}$ suggests the presence of the antiferromagnetic interactions between the spins of vanadium ions. The experimentally obtained value of the effective magnetic moment was $3.9 \mu_{\mathrm{B}}$ for the $\mathrm{Li}_{3} \mathrm{~V}_{2}\left(\mathrm{PO}_{4}\right)_{3} / \mathrm{Li}_{3} \mathrm{PO}_{4}$ composite, which perfectly corresponded to the $\mathrm{V}^{3+}$ ions $\left(3 \mathrm{~d}^{2}, \mathrm{~S}=1\right)$. The observed ZFCFC splitting below $\mathrm{T}<120 \mathrm{~K}$ suggests the presence of magnetically correlated regions (probably, ferromagnetically correlated clusters), in addition to the paramagnetic phase due to anti-site defects and the presence of $\mathrm{V}^{4+}$ ions. The existence of $\mathrm{V}^{4+}$ ions was directly confirmed by electron spin resonance measurements and the number of magnetic spins was estimated $(<10 \%)$. 
Author Contributions: Conceptualization, T.G., S.K. and N.S.; Methodology, T.G., Y.D. and T.C.; Investigation, M.C., R.B., I.Y., N.L., Y.D., D.T. and T.C.; Writing-original draft preparation, T.G.; Writing-review and editing, T.G., S.K. and N.S. All authors have read and agreed to the published version of the manuscript.

Funding: The reported research was funded by the Russian Science Foundation (grant no. 19-7910216).

Data Availability Statement: The study did not report any data.

Conflicts of Interest: The authors declare no conflict of interest. The funders had no role in the design of the study; in the collection, analyses, or interpretation of data; in the writing of the manuscript, or in the decision to publish the results.

\section{References}

1. Li, W.; Song, B.; Manthiram, A. High-voltage positive electrode materials for lithium-ion batteries. Chem. Soc. Rev. 2017, 46, 3006-3059. [CrossRef] [PubMed]

2. Hu, M.; Pang, X.; Zhou, Z. Recent progress in high-voltage lithium ion batteries. J. Power Sources 2013, 237, 229-242. [CrossRef]

3. Liu, C.; Massé, R.; Nan, X.; Cao, G. A promising cathode for Li-ion batteries: Li3V2(PO4)3. Energy Storage Mater. 2016, 4, 15-58. [CrossRef]

4. Rui, X.; Yan, Q.; Skyllas-Kazacos, M.; Lim, T.M. Li3V2(PO4)3 cathode materials for lithium-ion batteries: A review. J. Power Sources 2014, 258, 19-38. [CrossRef]

5. Tan, H.; Xu, L.; Geng, H.; Rui, X.; Li, C.; Huang, S. Nanostructured Li3V2(PO4)3 Cathodes. Small 2018, 14, 1800567. [CrossRef]

6. Liao, Y.; Li, C.; Lou, X.; Hu, X.; Ning, Y.; Yuan, F.; Chen, B.; Shen, M.; Hu, B. Carbon-coated Li3V2(PO4)3 derived from metal-organic framework as cathode for lithium-ion batteries with high stability. Electrochim. Acta 2018, 271, 608-616. [CrossRef]

7. Chen, Y.; Xiang, K.; Zhu, Y.; Xiao, L.; Chen, W.; Chen, X.; Chen, H. Bio-template fabrication of nitrogen-doped Li3V2(PO4)3/carbon composites from cattail fibers and their high-rate performance in lithium-ion batteries. J. Alloy. Compd. 2019, 782, 89-99. [CrossRef]

8. Ding, X.-K.; Zhang, L.-L.; Yang, X.-L.; Fang, H.; Zhou, Y.-X.; Wang, J.-Q.; Ma, D. Anthracite-Derived Dual-Phase Carbon-Coated Li3V2(PO4)3 as High-Performance Cathode Material for Lithium Ion Batteries. ACS Appl. Mater. Interfaces 2017, 9, 42788-42796. [CrossRef]

9. Ren, M.M.; Zhou, Z.; Gao, X.P.; Peng, W.X.; Wei, J.P. Core-Shell Li3V2(PO4)3@C Composites as Cathode Materials for Lithium-Ion Batteries. J. Phys. Chem. C 2008, 112, 5689-5693. [CrossRef]

10. Wang, J.; Liu, J.; Yang, G.; Zhang, X.; Yan, X.; Pan, X.; Wang, R. Electrochemical performance of Li3V2(PO4)3/C cathode material using a novel carbon source. Electrochim. Acta 2009, 54, 6451-6454. [CrossRef]

11. Zhang, L.L.; Liang, G.; Peng, G.; Zou, F.; Huang, Y.H.; Croft, M.C.; Ignatov, A. Significantly improved electrochemical performance in Li3V2(PO4)3/C promoted by SiO2 coating for lithium-ion batteries. J. Phys. Chem. C 2012, 116, 12401-12408. [CrossRef]

12. Lai, C.Y.; Wei, J.J.; Wang, Z.; Xu, Q.J.; Lu, Y.F.; Li, H.X. Li3V2(PO4)3/(SiO2 + C) composite with better stability and electrochemical properties for lithium ion batteries. Solid State Ion. 2015, 272, 121-126. [CrossRef]

13. Sun, H.-B.; Zhou, Y.-H.; Zhang, L.-L.; Yang, X.-L.; Cao, X.-Z.; Arave, H.; Fang, H.; Liang, G. Investigations on Zr incorporation into Li3V2(PO4)3/C cathode materials for lithium ion batteries. Phys. Chem. Chem. Phys. 2017, 19, 5155-5162. [CrossRef]

14. Ren, M.; Zhou, Z.; Li, Y.; Gao, X.P.; Yan, J. Preparation and electrochemical studies of Fe-doped Li3V2(PO4)3 cathode materials for lithium-ion batteries. J. Power Sources 2006, 162, 1357-1362. [CrossRef]

15. Ivanishchev, A.V.; Ushakov, A.V.; Ivanishcheva, I.A.; Churikov, A.V.; Mironov, A.V.; Fedotov, S.S.; Khasanova, N.R.; Antipov, E.V. Structural and electrochemical study of fast Li diffusion in Li3V2(PO4)3-based electrode material. Electrochim. Acta 2017, 230, 479-491. [CrossRef]

16. Gavrilova, T.P.; Khantimerov, S.M.; Fatykhov, R.R.; Yatsyk, I.V.; Cherosov, M.A.; Lee, H.S.; Vishwanathan, R.; Saravanan, K.; Suleimanov, N.M. Magnetic properties and vanadium oxidation state in $\alpha$-Li3V2(PO4)3/C composite: Magnetization and ESR measurements. Solid State Commun. 2021, 323, 114108. [CrossRef]

17. Park, M.; Zhang, X.; Chung, M.; Less, G.B.; Sastry, A.M. A review of conduction phenomena in Li-ion batteries. J. Power Sources 2010, 195, 7904-7929. [CrossRef]

18. Zhou, F.; Kang, K.; Maxisch, T.; Ceder, G.; Morgan, D. The electronic structure and band gap of LiFePO4 and LiMnPO4. Solid State Commun. 2004, 132, 181-186. [CrossRef]

19. Yin, S.-C.; Strobel, P.S.; Grondey, H.; Nazar, L.F. Li2.5V2(PO4)3: A Room-Temperature Analogue to the Fast-Ion Conducting High-Temperature $\gamma$-Phase of Li3V2(PO4)3. Chem. Mater. 2004, 16, 1456-1465. [CrossRef]

20. Tai, Z.; Zhu, W.; Shi, M.; Xin, Y.; Guo, S.; Wu, Y.; Chen, Y.; Liu, Y. Improving electrochemical performances of Lithium-rich oxide by cooperatively doping $\mathrm{Cr}$ and coating Li3PO4 as cathode material for Lithium-ion batteries. J. Colloid Interface Sci. 2020, 576, 468-475. [CrossRef]

21. Zhang, W.; Liang, L.; Zhao, F.; Liu, Y.; Hou, L.; Yuan, C. Ni-rich LiNi0.8Co0.1Mn0.1O2 coated with Li-ion conductive Li3PO4 as competitive cathodes for high-energy-density lithium ion batteries. Electrochim. Acta 2020, 340, 135871. [CrossRef] 
22. Wang, Y.; Zhang, X.; He, W.; Wei, C.; Cheng, Q. A review for the synthesis methods of lithium vanadium phosphate cathode materials. J. Mater. Sci. Mater. Electron. 2017, 28, 18269-18295. [CrossRef]

23. Lee, H.S.; Vishwanathan, R.; Saravanan, K.; Nagarathinam, M.; Law, M.; Wang, C.; Tripathi, A.; Palani, B. Key design considerations for synthesis of mesoporous $\alpha$-Li3V2(PO4)3/C for high power lithium batteries. Electrochim. Acta 2021, $372,137831$. [CrossRef]

24. Saravanan, K.; Mason, C.W.; Rudola, A.; Wong, K.H.; Balaya, P. The first report on excellent cycling stability and superior rate capability of Na3V2(PO4)3 for Sodium-ion batteries. Adv. Energy Mater. 2013, 3, 444-450. [CrossRef]

25. Du, K.; Wang, C.; Subasinghe, L.U.; Gajjela, S.R.; Law, M.; Rudola, A.; Balaya, P. A Comprehensive Study on the Electrolyte, Anode and Cathode for Developing Commercial Type Non-flammable Sodium-ion Battery. Energy Storage Mater. 2020, 29 , 287-299. [CrossRef]

26. Nizamov, F.A.; Togulev, P.N.; Abdullin, D.R.; Khantimerov, S.M.; Balaya, P.; Suleimanov, N.M. Antisite Defects and Valence State of Vanadium in Na3V2(PO4)3. Phys. Solid State 2016, 58, 475-480. [CrossRef]

27. Yang, G.; Ji, H.; Liu, H.; Qian, B.; Jiang, X. Crystal structure and electrochemical performance of Li3V2(PO4)3 synthesized by optimized microwave solid-state synthesis route. Electrochim. Acta 2010, 55, 3669-3680. [CrossRef]

28. Patoux, S.; Wurm, C.; Morcrette, M.; Rousse, G.; Masquelier, C. A comparative structural and electrochemical study of monoclinic Li3Fe2(PO4)3 and Li3V2(PO4)3. J. Power Sources 2003, 119-121, 278-284. [CrossRef]

29. Liu, H.; Yang, G.; Zhang, X.; Gao, P.; Wang, L.; Fang, J.; Pinto, J.; Jiang, X. Kinetics of conventional carbon coated-Li3V2(PO4)3 and nanocomposite Li3V2(PO4)3/graphene as cathode materials for lithium ion batteries. J. Mater. Chem. 2012, 22, 11039-11047. [CrossRef]

30. Cao, X.; Wu, H.; Ge, P.; Zhao, Y.; Zhu, L.; Liu, F.; Wang, J. Synthesis of Li3V2(PO4)3/C Composites as Cathode Materials for Lithium Ion Batteries via a Sol-Gel Method. Int. J. Electrochem. Sci. 2015, 10, 2997-3009.

31. Chen, Y.; Zhang, D.; Bian, X.; Bie, X.; Wang, C.; Du, F.; Jang, M.; Chen, G.; Wei, Y. Characterizations of the electrode/electrolyte interfacial properties of carbon coated Li3V2(PO4)3 cathode material in LiPF6 based electrolyte. Electrochim. Acta 2012, 79, 95-101. [CrossRef]

32. Yin, S.-C.; Grondey, H.; Strobel, P.; Anne, M.; Nazar, L.F. Electrochemical Property: Structure Relationships in Monoclinic Li3-yV2(PO4)3. J. Am. Chem. Soc. 2003, 125, 10402-10411. [CrossRef] [PubMed]

33. EasySpin. Available online: http:/ / www.easyspin.org (accessed on 1 February 2021).

34. Cahill, L.S.; Chapman, R.P.; Kirby, C.W.; Goward, G.R. The Challenge of Paramagnetism in Two-Dimensional 6,7Li Exchange NMR. Appl. Magn. Reson. 2007, 32, 565-581. [CrossRef]

35. De Gennes, P.G. Effects of Double Exchange in Magnetic Crystals. Phys. Rev. 1960, 118, 141-154. [CrossRef]

36. Heikes, R.R.; McGuire, T.R.; Happel, R.G. Role of Double Exchange in the Magnetic Structure of LixMn1-xSe. Phys. Rev. 1961, 121, 703-707. [CrossRef]

37. Pickart, S.J.; Nathans, R.; Shirane, G. Magnetic Structure Transitions in LixMn1-xSe. Phys. Rev. 1961, 121, 707-714. [CrossRef]

38. Eremina, R.M.; Gavrilova, T.P.; Yatsyk, I.V.; Zaripov, R.B.; Sukhanov, A.A.; Shustov, V.A.; Lyadov, N.M.; Chichkov, V.I.; Andreev, N.V. Magnetic Resonance Investigations of h-YbMnO3. Appl. Magn. Reson. 2016, 47, 869-879. [CrossRef]

39. Bykov, E.O.; Gavrilova, T.P.; Yatsyk, I.V.; Gilmutdinov, I.F.; Parfenov, V.V.; Kurbakov, A.I.; Eremina, R.M. Structural and magnetic properties of $\mathrm{Yb1}$-xSrxMnO3. Ceram. Int. 2019, 45, 10286-10294. [CrossRef]

40. Gavrilova, T.P.; Yagfarova, A.R.; Deeva, Y.A.; Yatsyk, I.V.; Gilmutdinov, I.F.; Cherosov, M.A.; Vagizov, F.G.; Chupakhina, T.I.; Eremina, R.M. Iron oxidation state in La0.7Sr1.3Fe0.7Ti0.3O4 and La0.5Sr1.5Fe0.5Ti0.5O4 layered perovskites: Magnetic properties. J. Phys. Chem. Solids 2021, 153, 109994. [CrossRef] 